\title{
Clinical effect of deproteinized calfblood extract eye gel for corneal epithelial defect
}

\author{
Chungang Zhang*1, Mingxia Wei ${ }^{2}$ \\ ${ }^{1}$ The Forth Hospital of Baotou, Baotou, Inner Mongolia, China \\ ${ }^{2}$ Baogang Hospital, Baotou, Inner Mongolia, China
}

Received: March 12, 2018

DOI: $10.14725 /$ dcc.v5n2p7

\author{
Accepted: April 22, 2018 \\ Online Published: June 10, 2018 \\ URL: http://dx.doi.org/10.14725/dcc.v5n2p7
}

\begin{abstract}
Objective: To observe the clinical effect of $20 \%$ deproteinized calfblood extract eye gel on the treatment of mechanical injury to corneal epithelium.

Methods: 120 cases of patients with corneal epithelial defect caused by mechanical injury were selected and randomly divided into observation group (60 eyes, deproteinized calfblood extract eye gel in use) and control group ( $0.3 \%$ ofloxacin eye drops in use). Both two groups of patients were given eye gel or eye drops 4 times per day. Moreover, the two groups of eye symptoms and corneal epithelial healing were observed on the $3^{r d}$ day and the $7^{\text {th }}$ day after drug usage respectively.

Results: The effective rates of $20 \%$ deproteinized calfblood extract eye gel on the treatment of mechanical corneal epithelial defect on the $3^{\text {rd }}$ day and the $7^{\text {th }}$ day were $78.33 \%$ and $93.33 \%$ respectively. Meanwhile, the effective rates of $0.3 \%$ ofloxacin eye drops were $55.00 \%$ and $71.67 \%$. The difference in the comparison of the effective rate between two groups was of statistical significance $(p<.05)$.

Conclusions: $20 \%$ deproteinized calfblood extract eye gel can significantly promote the healing of corneal epithelium in a short time, and it is worthy to be widely applied clinically.
\end{abstract}

Key Words: Deproteinized calfblood extract eye gel, Corneal epitheliums, Mechanical injury

Corneal epithelial injury is a clinically common ocular surface disease. Corneal epithelium is susceptible to traumatic surgery, chemical and bacterial elements, causing the occurrence of eye discomfort and visual disturbance, even worse, corneal perforation. Therefore, rapid and complete repair of corneal epithelium is an urgent problem for clinical ophthalmologists. The clinical effect of $20 \%$ deproteinized calfblood extract eye gel (produced by Shenyang Sinqi Pharmaceutical Co., Ltd.) on the treatment of corneal epithelial defect was observed and reported as follows.

\section{Data and methods}

\subsection{General Information}

120 cases of patients admitted to our hospital from June of 2013 to June of 2016 were selected, including 56 males and 64 females, aged 20 to 60 years. All of them were diagnosed as corneal epithelial defect caused by mechanical injury. The observation group consisted of 60 patients, with 29 males and 33 females, and the average age was $36.80 \pm$ 12.08 years; Another 60 patients were included in the control group, with 27 males and 31 females, and the average age was $37.15 \pm 11.32$ years. The differences in the sex constituent ratio and age between the two groups were sta-

*Correspondence: Chungang Zhang; E-mail: dcc70@ncspress.com; Address: The Forth Hospital of Baotou, Baotou, Inner Mongolia, China. 
tistically significant $(p>.05)$. According to the criteria for ference in corneal epithelial injury between the two groups grading symptoms and physical signs (see Table 1), the dif- was also of no statistical significance $(p>.05)$.

Table 1: Grading criteria of mechanical corneal epithelial injury

\begin{tabular}{lllll}
\hline & $\mathbf{0}$ & $\mathbf{1}$ & $\mathbf{2}$ & $\mathbf{3}$ \\
\hline Photophobia & None & Uncomfortable of light & Intolerable of low light & Hard to open eyes \\
$\begin{array}{l}\text { Eye pain } \\
\text { Conjunctiva hyperemia }\end{array}$ & None & A little pain & Obvious pain, tolerable & Obvious pain, intolerable \\
$\begin{array}{l}\text { Fluorescein vital staining spots } \\
\text { on corneal epitheliums }\end{array}$ & None & $<5$ spots & Moderate & Severe \\
\hline
\end{tabular}

\subsection{Methods}

\subsubsection{Treatment methods}

Patients in the observation group were given 20\% deproteinized calfblood extract eye gel (produced by Shenyang Sinqi Pharmaceutical Co., Ltd.); and the patients in the control group were given $0.3 \%$ ofloxacin eye drops (produced by Nanjing Tianlang Pharmaceutical Co., Ltd.). Both two groups of patients were given eye gel or eye drops 4 times per day, and were required to make a return visit on the $3^{\text {rd }}$ day and the $7^{\text {th }}$ day after drug usage respectively.

Grading criteria were established in accordance with patients' chief complaints and symptoms to judge the clinical effect and make a statistical analysis.

\subsubsection{Judgment standards of the clinical effect}

(1) Recovery: the symptoms disappeared, without conjunctiva hyperemia; the epithelial defect was healed, and the fluorescein staining was negative. (2) Valid: symptoms and signs were significantly relieved, with mild conjunctival hyperemia; and fluorescein staining range on the cornea was significantly narrowed. (3) Invalid: irritation symptoms and signs were not relieved significantly, with conjunctival hyperemia and no change in corneal fluorescein staining. The relevant formula was as follows: Effective rate $(\%)=$ (recovery + valid)/total number of eyes $\times 100 \%$.

\subsubsection{Statistical analysis}

With SPSS 13.0 statistical software applied, chi-square test was used to make a comparison in the recovery rate and the effective rate. The difference $(p<.05)$ was statistically significant.

\section{Results}

In the $3^{r d}$ return visit, the effective rates of the observation group and the control group were $78.33 \%$ and $55.00 \%$ respectively $\left(\chi^{2}=7.35, p=.007\right)$; on the $7^{\text {th }}$ day, the effective rates of the two groups were $93.33 \%$ and $71.67 \%$ respectively $\left(\chi^{2}=9.755, p=.002\right)$. The difference in comparison between the two groups either on the $3^{r d}$ day or the $7^{\text {th }}$ day was of statistical significance $(p<.05$, see Tables 2-3 and Figure 1).

Table 2: Comparison in the clinical effect on corneal epithelial defect between the two groups on the $3^{r d}$ day (n, \%)

\begin{tabular}{llllll}
\hline & n & Recovery & Valid & Invalid & Effective Rate (\%) \\
\hline Observation Group & 60 eyes & 23 & 24 & 13 & 78.33 \\
Control Group & 60 eyes & 17 & 16 & 27 & 55.00 \\
\hline
\end{tabular}

Table 3: Comparison in the clinical effect on corneal epithelial defect between the two groups on the $7^{\text {th }}$ day (n, \%)

\begin{tabular}{llllll}
\hline & $\mathbf{n}$ & Recovery & Valid & Invalid & Effective Rate (\%) \\
\hline Observation Group & 60 eyes & 35 & 21 & 4 & 93.33 \\
Control Group & 60 eyes & 25 & 18 & 17 & 71.67 \\
\hline
\end{tabular}

\section{Discussion}

Corneal epithelium constitutes the outermost layer of human cornea, a non-keratinized squamous epithelium with a thickness of approximately $50 \mu \mathrm{m}$. A variety of factors can give rise to corneal epithelial defect. The healing of corneal epithelial damage is accomplished by the migra- 
tion and proliferation of basal cells with a division function. A variety of active substances are involved in the process of corneal epithelial repair, and some changes in cell morphology and biochemistry occur with the help of glucose metabolism. ${ }^{[1]}$ In some minor wounds of the corneal epithelium, hemidesmosomes found in epidermis, basal cells and basilar membranes are opened, basal cells migrate and proliferate on basilar membranes, and hemidesmosomes are reassembled, forming a new epithelial layer. ${ }^{[2]}$ If the defect is large, pseudopods can protrude from adjacent normal epithelial cells and migrate to the epithelial defect area, which will be recovered in several weeks to months. Nerves in corneal tissues are densely distributed, even a few millimeters of damage can also stimulate patients' sensory nerve endings, resulting in foreign body sensation, soreness and pain. ${ }^{[3]}$ If the corneal epithelial injury cannot be repaired in a timely and effective manner, it will cause a series of com- plications such as corneal ulcer or dissolution, scars, etc., which affect the corneal transparency and lead to impaired vision. The conventional treatment of corneal epithelial defect is to apply antibiotics locally in order to enhance the local anti-infection ability. It mainly relies on the growth of the corneal membrane to repair cornea, and takes a long time to improve patients' symptoms. ${ }^{[4]}$ It is important to find a certain type of drug clinically to quickly and completely repair corneal epithelial defect. In recent years, drugs that are applied clinically to the treatment of corneal injury mainly play a role in the lubrication, nutrition and repair of the cornea. These drugs include epidermal augmentum factors, basic fibroblast growth factors, fibronectin, matrix metalloproteinase, collagen and so on. These drugs have a certain efficacy, but it is still not ideal, since these drugs have different degrees of neovascularization effects, which impair the healing of corneal epithelium. ${ }^{[5,6]}$

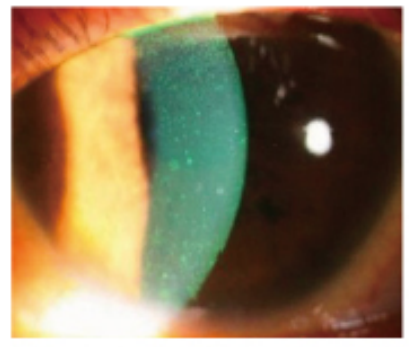

$0 \mathrm{~d}$

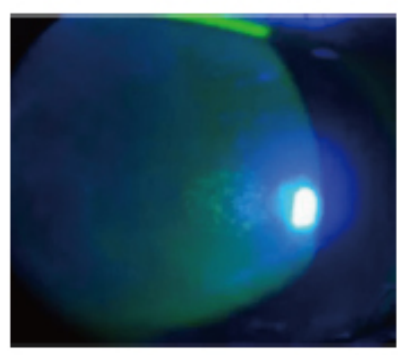

$0 \mathrm{~d}$

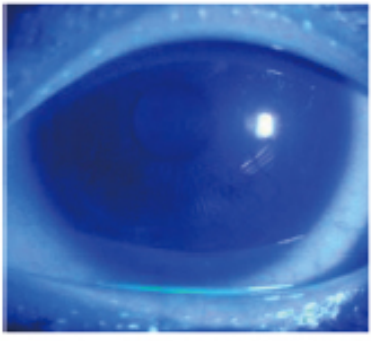

$3 \mathrm{~d}$

Experience group

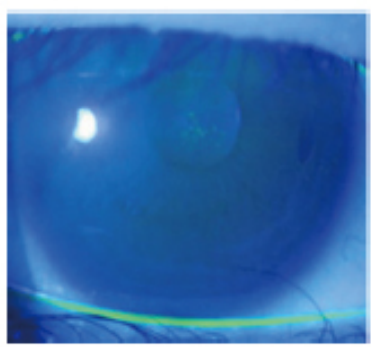

$3 \mathrm{~d}$

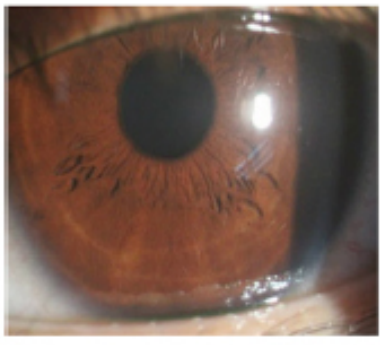

$7 \mathrm{~d}$

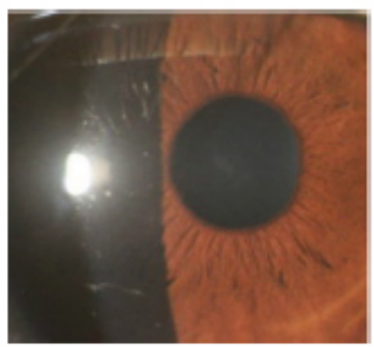

$7 \mathrm{~d}$

Control group

Figure 1: Comparison in the clinical effect on corneal epithelial defect between the two groups

Deproteinized calfblood extract, derived from quarantineinspected, vigorously growing calf serums, fetal livers and thymuses, going through a series of purification and filtration processes, is a type of small molecular drug, which consists of amino acids, low molecular peptides, nucleosides, glycolipids and other active substances. ${ }^{[7]}$ Deproteinized calfblood extract, a type of cell respiratory agonists, is a substance required for cell biosynthesis and metabolism. Its main pharmacological action is to enhance the synthesis of adenosine triphosphate, transport nutrient substances, promote tissue repair and proliferation. ${ }^{[8]}$ At the same time, deproteinized calfblood extract can transmute hyperplas- tic granulation tissues, reorganize collagenous tissues and avoid the formation of scars on corneal epithelium. ${ }^{[9]}$ Deproteinized calfblood extract can significantly alleviate the irritating sensation caused by corneal ulcer; it remains to be unknown whether this extract has an effect on the promotion of corneal neovascularization. ${ }^{[10]}$ Studies have confirmed that ${ }^{[11,12]}$ the application of deproteinized calfblood extract to eyes can improve local hypoxia and ischemic conditions and promote the repair and regeneration of nerve tissues, which is beneficial to the repair of corneal epithelium injury caused by surgery and inflammation. The eye gel, formulated with carboxymethyl cellulose sodium, can pro- 
long the contact time of drug with the ocular surface, deploy medicinal properties of deproteinized calfblood extract to the greatest effect, simultaneously lubricate the cornea and effectively improve the comfort degree of medication. ${ }^{[13]}$ Shen L et al. ${ }^{[14]}$ reported the effect of deproteinized calfblood extract on the treatment of corneal injury after corneal foreign body removal. It was indicated that, on the basis of self repairing mechanism of corneal epithelium, deproteinized calfblood extract can improve the nutritional status of the corneal surface, affirming its own effect.

This study showed that, in the comparison between the observation group (60 eyes treated by deproteinized calfblood extract) and the control group (60 eyes treated by $0.3 \%$ ofloxacin eye drops), the effective rate in the observation group on the $3^{\text {rd }}$ day was $78.33 \%$, and the effective rate in

\section{References}

[1] Li P. Chinese Ophthalmology. Beijing: People's Medical Publishing House; 2005 .

[2] Li H, Song H. Evaluation on the clinical effect of treating corneal epithelium damage with deproteinized calf blood extract or sodium hyaluronate. Acta Academiae Medicinae CPAPF. 2010; 19(3): 203 204.

[3] Zhang XY, Guo QL, Wu XF, et al. Effect of deproteinized calf blood extract eye gel on the corneal repair after phacoemulsification with $6 \mathrm{~mm}$ incision. Journal of Tianjin Medical University. 2016; 22(5): 455-457.

[4] Yu Y. Research advances in mechanism of herpes simplex keratitis. Chinese Journal of Experimental Ophthalmology. 2013; 31(2): 201-203.

[5] Yin H, Shen ZW, Jiang L, et al. Effect of deproteinized calf blood extract eye gel on cornea epithelial healing after off-flap Epi-LASIK. International Journal of Ophthalmology. 2013; 13(2): 271-273.

[6] Xiao ZN, Hu ZL. Current progress on clinical treatment and research advances of bullous keratopathy. International Journal of Ophthalmology. 2012; 21(7): 1277-1280.

[7] Cheng XK, Luo Y, Zhang YH, et al. The application of deproteinized calf blood extract eye gel to the treatment of poor healing of corneal epithelium after Lasek. Herald of Medicine. 2012; 31(5): 617-618. the control group was $55.00 \%$; the effective rate in the observation group on the $7^{\text {th }}$ day was $93.33 \%$, and the effective rate in the control group was $71.67 \%$. The difference in the comparison of the effective rate between the two groups was of statistical significance $(p<.05)$, indicating that $20 \%$ deproteinized calfblood extract can play a role in the early stage of corneal injury, with a significant effect. Since deproteinized calfblood extract is a type of biologics, it may be rejected due to patients' individual differences. Once allergic reaction occurs, the usage of this drug should be stopped immediately, with symptomatic treatment given. It is worthy of being noted in the clinical application. ${ }^{[15]}$

\section{Conflicts of Interest Disclosure}

The authors have no conflicts of interest related to this article.

[8] Niu XX, Li YF, Zhan LY. Clinical research of deproteinized calf blood extract eye gel for corneal epithelial defect. International Journal of Ophthalmology. 2014; 14(2): 1313-1315.

[9] Yan SB, Liu ZX. Effect of deproteinized calf blood extract eye gel on the treatment of keratopathy. Chinese Journal of Gerontology. 2013; 33(20): 5183-5184.

[10] Wu W, Li CY, Wang ZC, et al. Effects of deproteinized calf blood extract and recombinant human epithelial growth factor on mechanical corneal epithelial wound healing and neovascularization of rabbits. Recent Advances in Ophthalmology. 2014; 7(5): 401-404.

[11] Lv H, Liu Z, Li X, et al. Effect of lacrimal plugs combined with deproteinized calfblood extract eye gel for filamentary keratitis. J Ocul Biol Dis Infor. 2010; 3(5): 134-140. PMid: 23243481. https://doi.org/10.1007/s12177-011-9066-6

[12] Xu SJ, Liu LP, Chen JL. Clinical observation of eyelid suture joint deproteinized calf blood extract for malnutrition corneal ulcer treatment. International Journal of Ophthalmology. 2011; 11(11): 20112012.

[13] Zhang SQ, Tang MS, Fan ZY. Therapeutic effect of protein free calfblood extract eye gel on dry eye after pterygium surgery. Clinical Journal of Medical Officer. 2015; 43(7): 720-723.

[14] Shen L, Qin SY. Effect of deproteinized calf blood extract eye gel for corneal epithelial repair after corneal foreign body removal surgery. International Journal of Ophthalmology. 2016; 16(9): 1723-1725.

[15] Cai XF, Tan Y, Zhao Y, et al. Research Progress in Clinical Application of Deproteinized Calf Blood. China Pharmacist. 2016; 19(2): 338-341. 